\title{
Martensite Formation in Partially and Fully Austenitic Plain Carbon Steels
}

\begin{abstract}
S.M.C. VAN BOHEMEN and J. SIETSMA
The progress of martensite formation in plain carbon steels $\mathrm{Fe}-0.46 \mathrm{C}, \mathrm{Fe}-0.66 \mathrm{C}$, and $\mathrm{Fe}-0.80 \mathrm{C}$ has been investigated by dilatometry. It is demonstrated that carbon enrichment of the remaining austenite due to intercritical annealing of $\mathrm{Fe}-0.46 \mathrm{C}$ and $\mathrm{Fe}-0.66 \mathrm{C}$ does not only depress the start temperature for martensite, but also slows the progress of the transformation with temperature compared to full austenitization. In contrast, such a change of kinetics is not observed when the remaining austenite of lean-Si steel Fe-0.80C is stabilized due to a partial transformation to bainite, which suggests that the stabilization is not of a chemical but of a mechanical nature. The growth of bainite and martensite is accompanied by a shape change at the microstructural scale, which leads to plastic deformation and thus strengthening of the surrounding austenite. Based on this stabilizing mechanism, the athermal transformation kinetics is rationalized by balancing the increase in driving force corresponding to a temperature decrease with the increase in strain energy required for the formation of martensite in the strengthened remaining austenite.
\end{abstract}

DOI: $10.1007 / \mathrm{s} 11661-009-9796-2$

(C) The Author(s) 2009. This article is published with open access at Springerlink.com

\section{INTRODUCTION}

IN steels, the transformation from austenite to martensite usually takes place due to a decreasing temperature rather than as a function of time, which is referred to as an athermal transformation. ${ }^{[1-6]}$ It is well known that the mechanism of growth is displacive, but how the phase nucleates and which material properties determine the amount of martensite formed is even today not completely understood despite all the efforts to study this transformation in various systems. Besides the fundamental interest in the nature of the transformation, a better understanding of the material properties that influence the progress of the martensitic transformation can also be important in the development of new advanced high-strength steels (e.g., dualphase steels), because the mechanical properties are, to a large degree, dictated by both the volume fraction and distribution of martensite in the microstructure.

In the present study, dilatometry measurements have been conducted on three plain carbon steels with different carbon content to determine the progress of the austenite to martensite transformation. The primary aim of this investigation is to get a better understanding of the differences in the kinetics of martensite formation in lean-Si steels with a bainitic/austenitic or ferritic/austenitic microstructure as compared to a fully

S.M.C. VAN BOHEMEN, Researcher, formerly with the Department of Materials Science and Engineering, Delft University of Technology, Mekelweg 2, 2628 CD Delft, The Netherlands, is with Corus Research Development \& Technology, 1970 CA IJmuiden, The Netherlands. Contact e-mail: s.m.c.vanbohemen@gmail.com J. SIETSMA, Associate Professor, is with the Department of Materials Science and Engineering, Delft University of Technology.

Manuscript submitted July 15, 2008

Article published online February 21, 2009 austenitic microstructure. Due to the low $\mathrm{Si}$ content $(<0.4 \mathrm{wt} \mathrm{pct})$ of the steels studied, it is reasonable to assume that carbide precipitation during the partial bainitic transformation is not retarded, which means that no significant carbon enrichment of the remaining austenite takes place. All the experimental fraction curves are analyzed using the Koistinen-Marburger $(\mathrm{KM})$ equation $^{[5,6]}$ and yield valuable information on the stabilization mechanism of the austenite in the partially transformed samples.

In the second part of this investigation, we attempt to get more insight into the role of the austenite grain boundaries in the nucleation and growth of martensite. Although it is known that the $M_{s}$ temperature decreases with grain refinement, ${ }^{[7-11]}$ it is not well understood why the overall progress of martensite formation is virtually independent of the prior austenite grain size except for the early stage of transformation. The GreningerTroiano metallographic technique ${ }^{[1]}$ has been applied to get a better understanding of the spatial evolution of martensite in an austenitic matrix.

\section{EXPERIMENTAL}

The chemical composition of the three plain carbon steels used in the present study $(\mathrm{Fe}-0.46 \mathrm{C}, \mathrm{Fe}-0.66 \mathrm{C}$, and $\mathrm{Fe}-0.80 \mathrm{C}$ ) was measured with X-ray fluoresence (XRF) and is given in Table I. The cylindrical dilatometric samples were machined with a length of $10 \mathrm{~mm}$ and a diameter of $5 \mathrm{~mm}$, and the dilatation of the samples as a function of temperature and time was measured at Delft University of Technology using a Bähr 805 A/D dilatometer (Bähr-Thermoanalyse $\mathrm{GmbH}$, Hüllhorst, Germany). ${ }^{[12]}$ The temperature was controlled using a thermocouple spot welded onto the center of the sample. 
Table I. Chemical Composition of the Steels (Weight Percent) Together with the Parameters $\alpha_{m}, T_{\mathrm{KM}}$, and $M_{s}$ Derived from Figure 1

\begin{tabular}{lccccccccccc}
\hline Alloy & $\mathrm{C}$ & $\mathrm{Mn}$ & $\mathrm{Si}$ & $\mathrm{Ni}$ & $\mathrm{Cr}$ & $\mathrm{Cu}$ & $\mathrm{P}$ & $\mathrm{S}$ & $\alpha_{m}\left(\mathrm{~K}^{-1}\right)$ & $T_{\mathrm{KM}}\left({ }^{\circ} \mathrm{C}\right)$ & $M_{s}\left({ }^{\circ} \mathrm{C}\right)$ \\
\hline $\mathrm{Fe}-0.46 \mathrm{C}$ & 0.46 & 0.71 & 0.26 & 0.1 & 0.2 & 0.23 & 0.002 & 0.03 & 0.0168 & 308 & 315 \\
$\mathrm{Fe}-0.66 \mathrm{C}$ & 0.66 & 0.69 & 0.3 & 0.1 & 0.2 & 0.17 & $-\overline{0}$ & 0.03 & 0.0146 & 258 & 264 \\
$\mathrm{Fe}-0.80 \mathrm{C}$ & 0.80 & 0.61 & 0.3 & 0.2 & 0.3 & 0.23 & 0.012 & 0.04 & 0.0131 & 219 & 231 \\
\hline
\end{tabular}

Table II. Experimental Details and Results of Martensite Formation in the Remaining Austenite after Intercritical Annealing of Fe-0.46C and Fe-0.66C

\begin{tabular}{lcccccc}
\hline Alloy & $\begin{array}{c}T_{i c} \\
\left({ }^{\circ} \mathrm{C}\right)\end{array}$ & $\begin{array}{c}t_{i c} \\
(\mathrm{Min})\end{array}$ & $f^{\alpha_{a}}$ & $\begin{array}{c}x_{\mathrm{C}}^{\gamma} \\
(\mathrm{Wt} \mathrm{Pct})\end{array}$ & $\begin{array}{c}T_{\mathrm{KM}} \\
\left({ }^{\circ} \mathrm{C}\right)\end{array}$ & $\begin{array}{c}\alpha_{m} \\
\left(\mathrm{~K}^{-1}\right)\end{array}$ \\
\hline $\mathrm{Fe}-0.46 \mathrm{C}$ & 724 & 30 & 0.41 & 0.77 & 233 & 0.0135 \\
$\mathrm{Fe}-0.46 \mathrm{C}$ & 731 & 20 & 0.34 & 0.69 & 248 & 0.0142 \\
$\mathrm{Fe}-0.46 \mathrm{C}$ & 736 & 12 & 0.30 & 0.65 & 255 & 0.0145 \\
$\mathrm{Fe}-0.66 \mathrm{C}$ & 726 & 15 & 0.18 & 0.80 & 236 & 0.0134 \\
$\mathrm{Fe}-0.66 \mathrm{C}$ & 740 & 8 & 0.09 & 0.72 & 250 & 0.0140 \\
\hline
\end{tabular}

To investigate the influence of the carbon content on the evolution of martensite formation, three different heat treatments were applied to three steel grades. In treatment 1 , the three steels were fully austenitized at $T_{\text {aus }}=900{ }^{\circ} \mathrm{C}$ for 2 minutes and subsequently cooled to room temperature in the dilatometer. In treatment 2 , measurements were performed to determine the martensitic transformation kinetics for $\mathrm{Fe}-0.46 \mathrm{C}$ and $\mathrm{Fe}-0.66 \mathrm{C}$ when quenching from an intercritical (in the $\alpha+\gamma$ region of the phase diagram) holding. To this purpose, the as-received steels with a ferritic-pearlitic microstructure were heated to various temperatures in the range of $720{ }^{\circ} \mathrm{C}$ to $740{ }^{\circ} \mathrm{C}$ (Table II), held at that temperature to form, besides ferrite, a certain fraction of austenite, and subsequently cooled to room temperature, during which the austenite transforms to martensite. In treatment 3 , dilatometry experiments were performed on steel $\mathrm{Fe}-0.80 \mathrm{C}$ to investigate the effect of a partial pearlitic or bainitic transformation on the progress of the subsequent transformation of the remaining austenite to martensite. For this, fully austenitized samples were rapidly cooled to various temperatures in the range of $275^{\circ} \mathrm{C}$ to $425{ }^{\circ} \mathrm{C}$ and held at that temperature for a specific time to partially transform the austenite to bainite (Table III). The transformation was interrupted and, during the cooling, the remaining austenite transformed to martensite. The volume fraction of bainite at the end of the bainitic holding was determined from the measured dilatation signal, normalizing to the dilatation corresponding to the full transformation to bainite for $\mathrm{Fe}-0.80 \mathrm{C}$. The fraction bainite is linearly related to the dilatation accompanying the transformation.

For an unambiguous analysis of the dilatometry results, it is important to have an estimate of the thermal gradient in the axial direction of the sample, and therefore, a second thermocouple was welded approximately $4 \mathrm{~mm}$ from the center of the sample in some of the experiments. In order to minimize thermal gradients in the sample, which can lead to inaccuracies in the measured kinetics, helium quench gas was not used in
Table III. Partial Bainitic Transformation Experiments on Fe-0.80C; $\alpha_{m}=0.0131 \mathrm{~K}^{-1}$ for All Experiments

\begin{tabular}{lclc}
\hline$T_{b}\left({ }^{\circ} \mathrm{C}\right)$ & $t_{b}(\mathrm{Min})$ & $f^{\alpha_{b}}$ & $T_{\mathrm{KM}}\left({ }^{\circ} \mathrm{C}\right)$ \\
\hline 275 & 9 & 0.52 & 174 \\
275 & 25 & 1 & - \\
325 & 2 & 0.11 & 209 \\
325 & 3 & 0.29 & 200 \\
325 & 4 & 0.49 & 185 \\
325 & 5 & 0.70 & 167 \\
325 & 6 & 0.84 & 153 \\
325 & 12 & 1 & - \\
375 & 1.5 & 0.48 & 193 \\
375 & 5 & 1 & - \\
425 & 0.5 & 0.47 & 199 \\
425 & 3 & 1 & - \\
$650^{*}$ & 1 & 0.61 & - \\
$650^{*}$ & 5 & 1 & \\
\hline
\end{tabular}

the temperature range of martensite formation. For example, in a typical experiment, to measure the martensitic transformation kinetics in the fully austenitic steels $\mathrm{Fe}-0.46 \mathrm{C}, \mathrm{Fe}-0.66 \mathrm{C}$, and $\mathrm{Fe}-0.80 \mathrm{C}$, each sample was cooled to approximately $350{ }^{\circ} \mathrm{C}$ with a cooling rate in the range of $70{ }^{\circ} \mathrm{C} / \mathrm{s}$ to $100{ }^{\circ} \mathrm{C} / \mathrm{s}$ using $\mathrm{He}$ gas, followed by natural cooling to room temperature. The dilatation as a function of temperature indicated that no ferrite or bainite formation occurred during cooling with the cooling rates employed. The experimental results were highly reproducible, and also samples that were given a homogenization treatment prior to the heat treatment showed identical results as the as-received samples, which indicates that the distribution of substitutional elements such as $\mathrm{Mn}$ is homogeneous in the as-received material.

The final microstructures of the dilatometry samples were characterized using optical microscopy in order to confirm the presence of ferrite in the intercritically annealed steels $\mathrm{Fe}-0.46 \mathrm{C}$ and $\mathrm{Fe}-0.66 \mathrm{C}$, and to demonstrate the existence of bainite in the partially transformed sample $\mathrm{Fe}-0.80 \mathrm{C}$. Furthermore, the volume fractions were determined from the micrographs for comparison with the volume fractions evaluated from the dilatometry curves.

\section{RESULTS}

\section{A. Composition Dependence of $\gamma \rightarrow \alpha^{\prime}$}

According to the method explained in Reference 13, the fraction of martensite as a function of temperature 
was determined from dilatation curves measured during cooling of steels $\mathrm{Fe}-0.46 \mathrm{C}, \mathrm{Fe}-0.66 \mathrm{C}$, and $\mathrm{Fe}-0.80 \mathrm{C}$ with a fully austenitic microstructure (Figure 1). The solid lines through the data represent least-squares fits to the KM equation, ${ }^{[5]}$ which describes the volume fraction of martensite as a function of temperature as

$$
f=1-\exp \left(-\alpha_{m}\left(T_{\mathrm{KM}}-T\right)\right)
$$

in which $\alpha_{m}$ is the rate parameter ${ }^{[6]}$ and $T_{\mathrm{KM}}$ the socalled theoretical martensite-start temperature, which can be somewhat lower than $M_{s}$ (Figure 1) depending on the austenitizing treatment, as will be explained in detail later in this article. The values of $T_{\mathrm{KM}}$ and $\alpha_{m}$ extracted from the least-squares fits are given in Table I.

Comparison of the experimental fraction curves shown in Figure 1 and the values of $\alpha_{m}$ given in Table I strongly suggests that the chemical composition determines the progress of transformation not only by its effect on $M_{s}$, but also the kinetics, i.e., the increase in volume fraction of martensite with decreasing temperature below $M_{s}$, is dependent on the composition. To strengthen this proposition, the composition dependence of the martensitic transformation kinetics has been systematically investigated by the present authors ${ }^{[14]}$ on the basis of complementary experimental data reported in the literature on the progress of martensite formation in other Fe alloys. ${ }^{[15,16]}$ Based on the fits of all experimental data to Eq. [1], it was proposed that the composition dependence of the rate parameter $\alpha_{m}$ can be described by a simple linear equation, similar to the well-known Andrews' empirical relationship between $M_{\mathrm{s}}$ and composition, ${ }^{[17]}$ as

$$
\begin{aligned}
\alpha_{m}\left(\mathrm{~K}^{-1}\right)= & 0.0224-0.0107 x_{\mathrm{C}}-0.0007 x_{\mathrm{Mn}} \\
& -0.00005 x_{\mathrm{Ni}}-0.00012 x_{\mathrm{Cr}}-0.0001 x_{\mathrm{Mo}}
\end{aligned}
$$

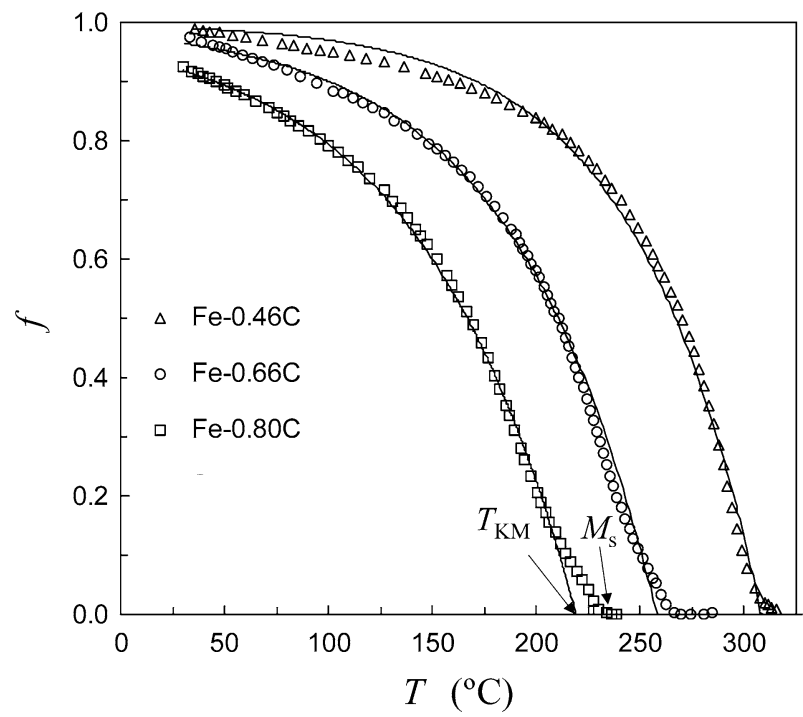

Fig. 1-Experimental and calculated curves of the martensite fraction $f$ as a function of temperature $T$ for steels Fe-0.46C, Fe-0.66C, and $\mathrm{Fe}-0.80 \mathrm{C}$ with the concentration $x$ in weight percent. Also, an empirical equation for $T_{\mathrm{KM}}$ was determined, which yields

$T_{\mathrm{KM}}\left({ }^{\circ} \mathrm{C}\right)=462-273 x_{\mathrm{C}}-26 x_{\mathrm{Mn}}-16 x_{\mathrm{Ni}}-13 x_{\mathrm{Cr}}-30 x_{\mathrm{Mo}}$

The coefficients in this equation are in fair agreement with those in the empirical equations of $M_{s}$, as reported in References 18 and 19. Based on the evidence of Figure 1, and more generally on the composition dependence of $\alpha_{m}$, it would be expected that in the case of chemical stabilization (carbon enrichment) of the austenite during intercritical annealing, as for example, in the processing of dual phase steels, the martensitic transformation in the remaining austenite does, as a consequence of the higher carbon content, not only start at lower temperature but also evolve at a lower rate compared to the transformation in fully austenitized steel. In order to verify this, the martensitic transformation in intercritically annealed samples of Fe-046C and $\mathrm{Fe}-0.66 \mathrm{C}$ was investigated.

\section{B. Effect of Intercritical Annealing on $\gamma_{R} \rightarrow \alpha^{\prime}$}

The intercritical annealing temperature $T_{i c}$ of $\mathrm{Fe}-0.46 \mathrm{C}$ and $\mathrm{Fe}-0.66 \mathrm{C}$ was varied to obtain different volume fractions of remaining austenite $\left(1-f^{\alpha_{a}}\right)$ with different carbon contents (Table II). The carbon content of the intercritical austenite is calculated by

$$
x_{\mathrm{C}}^{\gamma}=\frac{x_{0}-f^{\alpha_{a}} x_{\mathrm{C}}^{\alpha}}{1-f^{\alpha_{a}}}
$$

with $f^{\alpha_{a}}$ the volume fraction of allotriomorphic ferrite. The equilibrium concentration of carbon in ferrite $x_{\mathrm{C}}^{\alpha}$ is in the range of 0.015 to $0.02 \mathrm{wt}$ pct for the chosen temperatures $T_{i c}$. Figure 2(a) shows the ferrite-martensite microstructure of the $\mathrm{Fe}-0.46 \mathrm{C}$ sample that was annealed at $T_{i c}=736{ }^{\circ} \mathrm{C}$ for 12 minutes and subsequently cooled to room temperature. The volume fraction of ferrite in the microstructure is in fair agreement with the fraction $f^{\alpha_{a}}=0.30$ given in Table II. The progress of martensite formation in the remaining austenite was determined from the dilatometry curves analogous to the method described in Reference 13 . Figure 3 shows the martensite fraction curves for three $\mathrm{Fe}-0.46 \mathrm{C}$ samples that were, respectively, fully austenitized, annealed at $T_{i c}=736{ }^{\circ} \mathrm{C}$ and $T_{i c}=724{ }^{\circ} \mathrm{C}$. The solid lines represent the best fits according to

$$
f=f^{\alpha_{a}}+\left(1-f^{\alpha_{a}}\right)\left(1-\exp \left(-\alpha_{m}\left(T_{\mathrm{KM}}-T\right)\right)\right)
$$

in which $T_{\mathrm{KM}}$ and $\alpha_{m}$ are, respectively, the start temperature and rate parameter for martensite formation in the remaining austenite. For the $\mathrm{Fe}-0.46 \mathrm{C}$ sample annealed at $T_{i c}=736{ }^{\circ} \mathrm{C}$, which has a volume fraction of allotriomorphic ferrite $f^{\alpha_{a}}=0.30$ and $x_{\mathrm{C}}^{\gamma}=0.65$ wt pct, $T_{\mathrm{KM}}=255^{\circ} \mathrm{C}$, and $\alpha_{m}=0.0145 \mathrm{~K}^{-1}$. These values of $T_{\mathrm{KM}}$ and $\alpha_{m}$ are in close agreement with the values determined for fully austenitic samples Fe-0.66C (Table I). Furthermore, it is noted that the extracted fit 

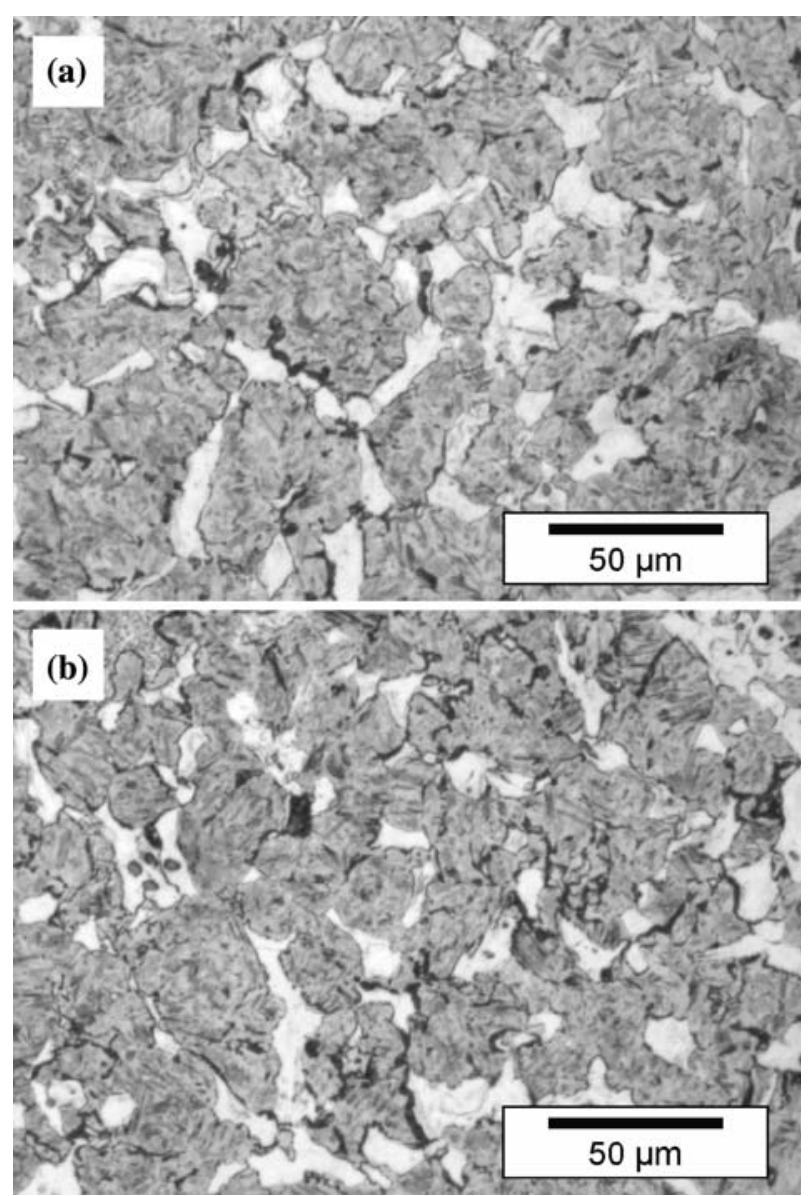

Fig. 2-Microstructures of (a) Fe-0.46C intercritically annealed at $T_{i c}=736{ }^{\circ} \mathrm{C}$ and $(b) \mathrm{Fe}-0.66 \mathrm{C}$ annealed at $T_{i c}=726^{\circ} \mathrm{C}$ showing ferrite and martensite.

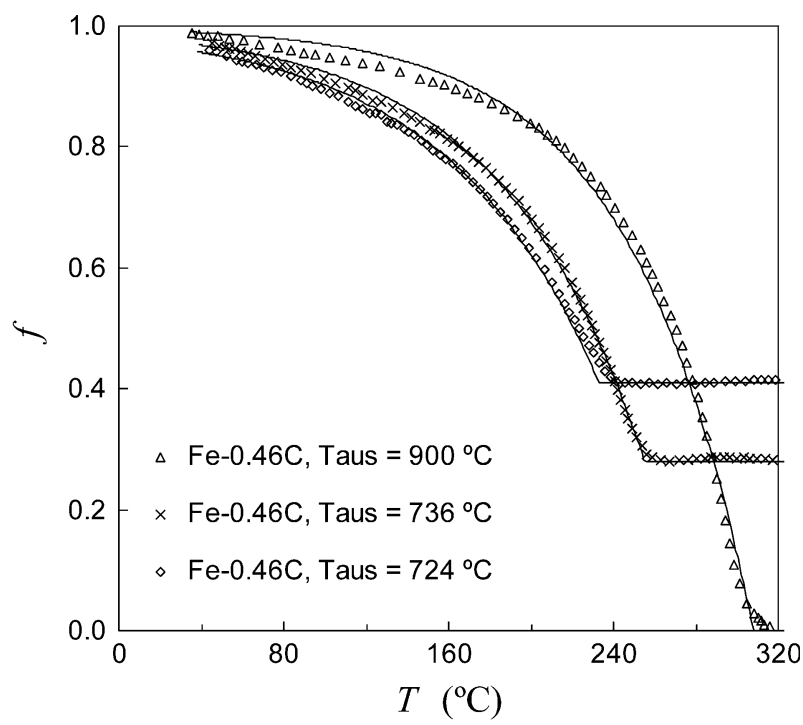

Fig. 3-Fraction $f$ of martensite as a function of temperature $T$ in $\mathrm{Fe}-0.46 \mathrm{C}$ samples intercritically annealed at $736{ }^{\circ} \mathrm{C}$ and $724{ }^{\circ} \mathrm{C}$. The solid lines represent the best fits with the KM equation from which the start temperature and the rate parameter are extracted. As a reference, the progress of the transformation in a fully austenitic sample from Figure 1 is also shown.

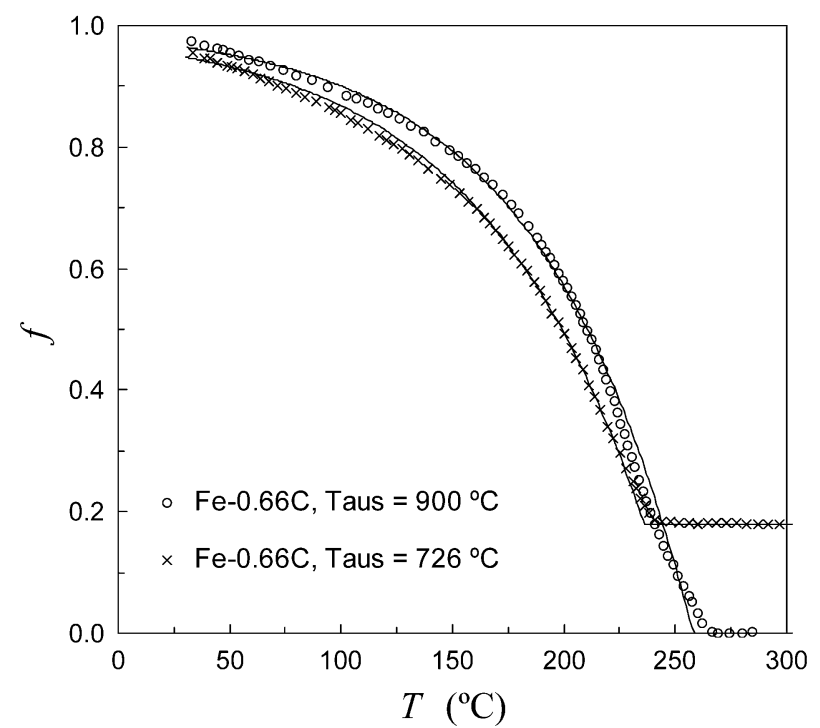

Fig. 4-Progress of martensite formation (fraction $f$ ) as a function of temperature $T$ in $\mathrm{Fe}-0.66 \mathrm{C}$ intercritically annealed at $726^{\circ} \mathrm{C}$ compared to the kinetics in a fully austenitic sample.

parameters $T_{\mathrm{KM}}=235^{\circ} \mathrm{C}$ and $\alpha_{m}=0.0136 \mathrm{~K}^{-1}$ $\left(f^{\alpha_{a}}=0.41\right.$ and $\left.x_{\mathrm{C}}^{\gamma}=0.77 \mathrm{wt} \mathrm{pct}\right)$ for the sample annealed at $T_{i c}=724{ }^{\circ} \mathrm{C}$ approach the kinetic parameters of $\mathrm{Fe}-0.80 \mathrm{C}$ (Table I), indicating that the remaining austenite has a nearly eutectoid composition. For Fe-0.66C, similar results were obtained, as seen in Figure 4, which shows the fraction curves for both a fully austenitized sample and a sample annealed at $T_{i c}=$ $726^{\circ} \mathrm{C}$. The ferrite-martensite microstructure of the Fe-0.66C sample annealed at $T_{i c}=726^{\circ} \mathrm{C}$ is shown in Figure 2(b). The values of $T_{\mathrm{KM}}$ and $\alpha_{m}$ derived from the best fits for $\mathrm{Fe}-0.66 \mathrm{C}$ are also listed in Table II.

Analysis of the values of $T_{\mathrm{KM}}$ and $\alpha_{m}$ derived for all intercritical annealed samples of $\mathrm{Fe}-0.46 \mathrm{C}$ and $\mathrm{Fe}-0.66 \mathrm{C}$ given in Table II shows a clear correlation, which confirms that $\alpha_{m}$ is changed due to chemical stabilization of austenite. All the parameters $\alpha_{m}$ and $T_{\mathrm{KM}}$ from Table I and Table II are plotted in Figure 5 (solid squares) to demonstrate this correlation. The linear trend in the solid squares is consistent with Eqs. [2] and [3]. The error bars in Figure 5 give a measure of the inaccuracy in the evaluated fit parameters $\alpha_{m}$ and $T_{\mathrm{KM}}$ and are determined by the calculation of fraction curves that deviate from the best fits but are still acceptable. The inaccuracy appears to be somewhat larger when the volume fraction of remaining austenite is smaller.

\section{Effect of a Partial Bainitic Transformation on $\gamma_{R} \rightarrow \alpha^{\prime}$}

In this section, the effect of a partial bainitic transformation on the subsequent transformation of the remaining austenite to martensite is discussed. A recent study by Jacques et al. showed that the bainitic transformation of a $0.38 \mathrm{wt}$ pct $\mathrm{Si}$ steel goes nearly to completion. ${ }^{[20]}$ Based on Mössbauer spectroscopy, they found that the final microstructure contained less than 2 vol pct retained austenite, probably present in the 


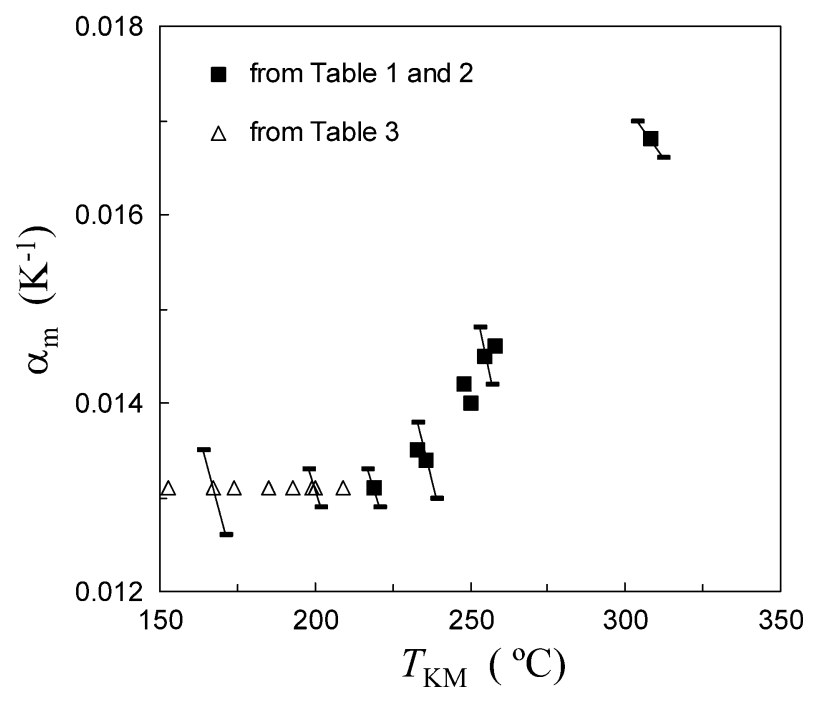

Fig. 5-Correlation between the KM parameters $\alpha_{m}$ and $T_{\mathrm{KM}}$ (Eq. [1]) for a fully austenitic or a ferritic/austenitic microstructure (Tables I and II) is different from the relationship between $\alpha_{m}$ and $T_{\mathrm{KM}}$ for a bainitic/austenitic microstructure (Table III).

form of thin austenite films between the bainitic platelets and, therefore, not visible in SEM micrographs. Based on the result from Reference 20, that carbon enrichment of the remaining austenite in a steel with $0.38 \mathrm{wt}$ pct $\mathrm{Si}$ is negligibly small, steel $\mathrm{Fe}-0.80 \mathrm{C}$ with approximately 0.3 wt pet $\mathrm{Si}$ was chosen in the present study to examine the effect of a partially bainitic transformation, during which $x_{\mathrm{C}}^{\gamma}$ can be assumed constant, on the subsequent decomposition of the remaining austenite to martensite. The evolution of martensite in partially bainitic samples is compared to the results obtained for intercritically annealed samples, which can be well explained by chemical stabilization of the remaining austenite, as demonstrated earlier.

Samples of $\mathrm{Fe}-0.80 \mathrm{C}$ were austenitized at $800{ }^{\circ} \mathrm{C}$ for 1 minute and subsequently held at various temperatures to investigate the stabilization effect of the formation of bainite on the remaining austenite. The isothermal transformation was interrupted at various stages, and during cooling, the start and progress of martensite formation in the remaining austenite was measured by dilatometry. The details of the partial transformation experiments are listed in Table III. As an example, three fraction curves are shown in Figure 6 for samples that were partially transformed to bainite at $325^{\circ} \mathrm{C}$ for different times. The solid lines through the data are the best fits calculated with Eq. [5], and it is found that all experimental fraction curves can be well described using $\alpha_{m}=0.0131 \mathrm{~K}^{-1}$, which is equal to the rate parameter for martensite formation in a fully $\mathrm{Fe}-0.80 \mathrm{C}$ austenitic sample austenitized at $800{ }^{\circ} \mathrm{C}$ for 1 minute. For comparison, the fraction curve corresponding to this fully austenitic sample is also shown in Figure 6. The values of $T_{\mathrm{KM}}$ derived from the best fits are given in Table III. Figure 7 shows the micrographs of samples that were isothermally held at $325^{\circ} \mathrm{C}$ for 2,4 , and 6 minutes. These microstructures demonstrate the evolution of bainite formation, and the corresponding volume

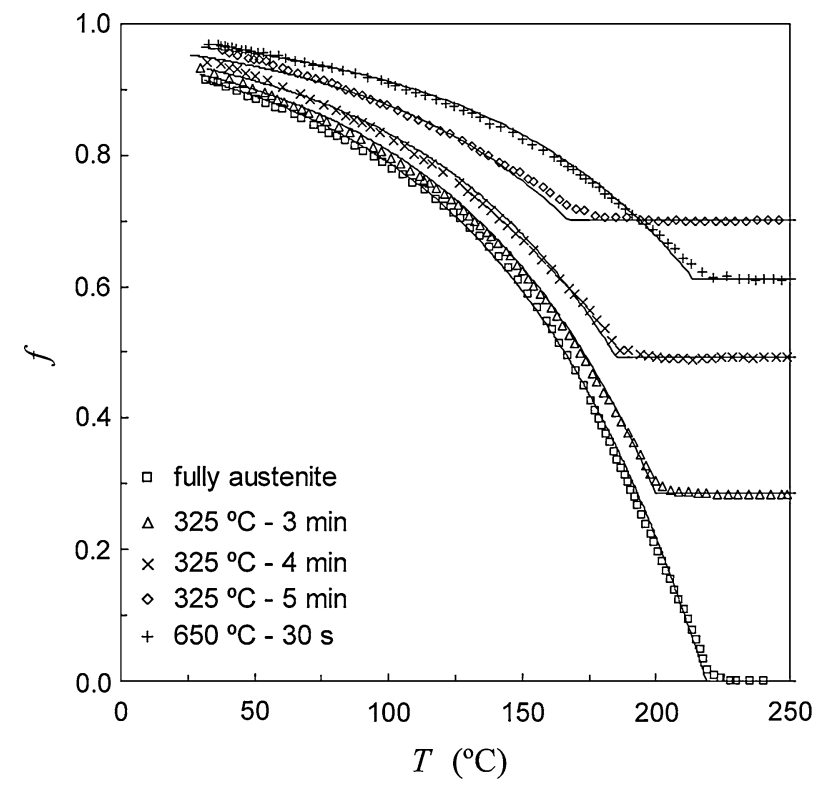

Fig. 6-Fraction of martensite $f$ as a function of temperature $T$ in $\mathrm{Fe}-0.80 \mathrm{C}$ samples partially transformed to bainite at $325^{\circ} \mathrm{C}$ for 3,4 , and $5 \mathrm{~min}$. The solid lines represent the fits with the $\mathrm{KM}$ equation from which the start-temperature $T_{\mathrm{KM}}$ is extracted; $\alpha_{m}=0.0131 \mathrm{~K}^{-1}$ for all curves. For comparison, the transformations in a fully austenitic sample (open squares) and a partially pearlitic sample $(+)$ are also shown.

fractions given in the caption of Figure 7 roughly agree with the values listed in Table III.

The values of $T_{\mathrm{KM}}$ are plotted against the volume fraction of bainite in Figure 8. For the different transformation times at $T_{b}=325{ }^{\circ} \mathrm{C}$, it is seen that $T_{\mathrm{KM}}$ decreases approximately linearly with the fraction transformed. Also, the dependence of $T_{\mathrm{KM}}$ on the bainite transformation temperature was investigated. At the other temperatures, a fraction of bainite of about 0.5 was formed, and Figure 8 shows that the stabilization effect becomes stronger at lower temperatures.

Figure 6 also shows the evolution of martensite formation in a sample that was partially transformed (61 vol pct) to pearlite at $650{ }^{\circ} \mathrm{C}$. Also, the kinetics of martensite formation in this partially pearlitic sample can be well described using a rate parameter $\alpha_{m}=0.0131 \mathrm{~K}^{-1}$, and a smaller depression of $T_{\mathrm{KM}}$ is observed as compared to the partially bainitic samples (also Figure 8).

The observation in Figure 8 that $T_{\mathrm{KM}}$ decreases with increasing fraction of bainite indicates that stabilization of the remaining austenite has occurred due to the bainitic transformation. However, it is also seen that the kinetics of martensite formation in all the partially bainitic samples can be well described using a constant value of the rate parameter $\alpha_{m}=0.0131 \mathrm{~K}^{-1}$. Figure 5 shows that the correlation between $\alpha_{m}$ and $T_{\mathrm{KM}}$ for partially bainitic samples $\mathrm{Fe}-0.80 \mathrm{C}$ (open triangles) is different from the trend between $\alpha_{m}$ and $T_{\mathrm{KM}}$ corresponding chemical stabilization (solid squares), as obtained for the intercritically annealed samples of $\mathrm{Fe}-0.46 \mathrm{C}$ and $\mathrm{Fe} 0.66 \mathrm{C}$ discussed earlier. This indicates that the stabilization of the austenite due to the partial bainitic transformation is not of a chemical nature. 

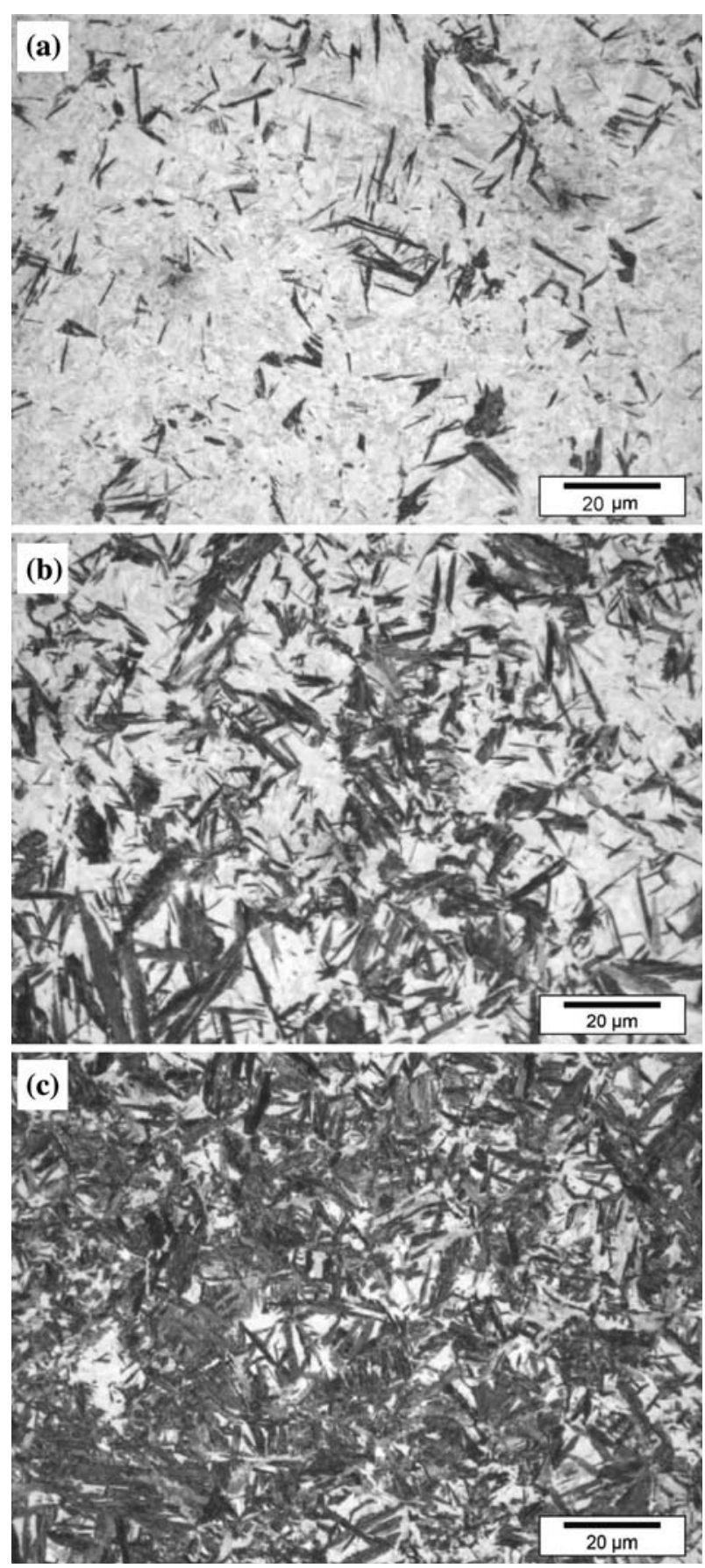

Fig. 7-Optical micrographs corresponding to the evolution of isothermal bainite formation in $\mathrm{Fe}-0.80 \mathrm{C}$ at $325^{\circ} \mathrm{C}$ after $(a) 2 \mathrm{~min}$ (15 vol pct), (b) $4 \mathrm{~min}$ (44 vol pct), and (c) $6 \mathrm{~min}$ (79 vol pct).

The conclusion drawn, viz. that the stabilization cannot be of a chemical nature, is strengthened by the following reasoning and analysis of the dilatometry results, which demonstrates that an explanation in terms of chemical stabilization is not self-consistent. If, contrary to the general opinion on lean-Si steels, carbon enrichment in austenite is assumed to occur in Fe-0.80$0.3 \mathrm{Si}$ during the partial transformation to bainite, the bainitic transformation after prolonged holding at which no length change is observed is considered to be

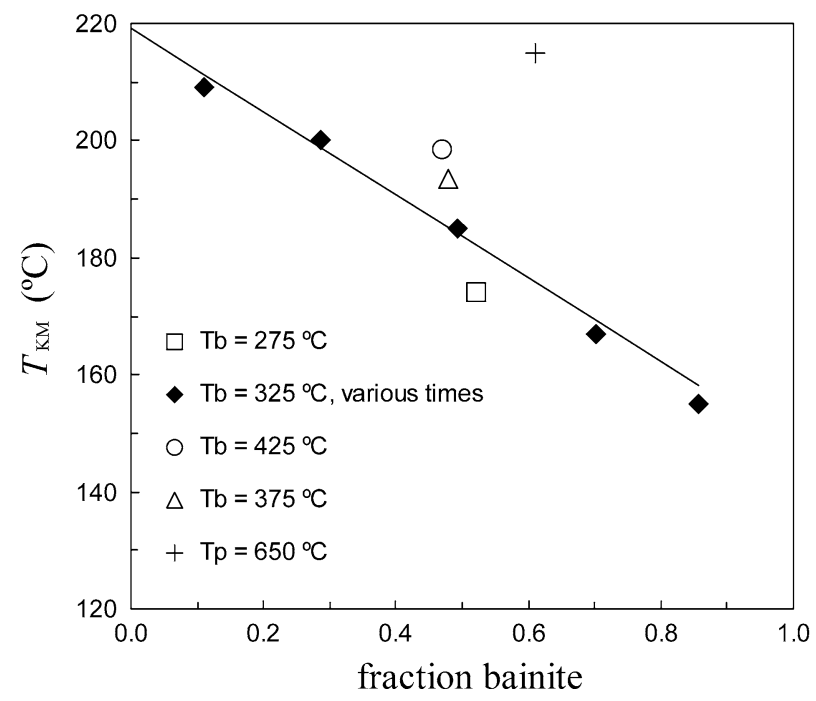

Fig. 8 - Start-temperature $T_{\mathrm{KM}}$ of martensite formation in Fe-0.80C samples partially transformed to bainite at different temperatures and for different times at $T_{b}=325^{\circ} \mathrm{C}$. The solid line represents the linear dependence, which gives the best agreement with the observed decrease of $T_{\mathrm{KM}}$ with increasing fraction bainite at $T_{b}=325^{\circ} \mathrm{C}\left(x_{\mathrm{C}}^{\gamma}\right.$ constant).

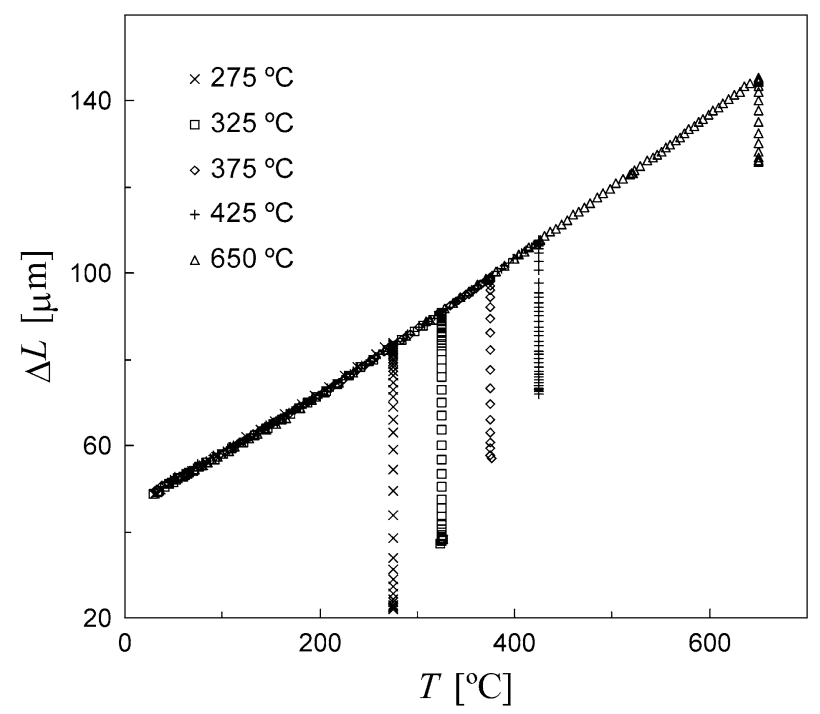

Fig. 9- Thermal contraction of Fe- $0.80 \mathrm{C}$ samples, represented by the length change $\Delta L$, as a function of temperature $T$ after prolonged holding at various bainite formation temperatures. The thermal expansion is seen to be similar to a sample completely transformed to pearlite at $650{ }^{\circ} \mathrm{C}$.

incomplete, the so-called "incomplete reaction phenomenon." ${ }^{[21]}$ This implies a significant increasing fraction of remaining austenite with increasing bainitic holding temperature $T_{b}$, which affects the thermal expansion/ contraction during cooling to room temperature. However, for the four different temperatures $T_{b}$ in the range $275{ }^{\circ} \mathrm{C}$ to $425{ }^{\circ} \mathrm{C}$, the thermal expansion is virtually identical, as shown in Figure 9. In fact, the thermal expansion is also the same as for a sample that was completely transformed to pearlite at $T=650^{\circ} \mathrm{C}$, and 

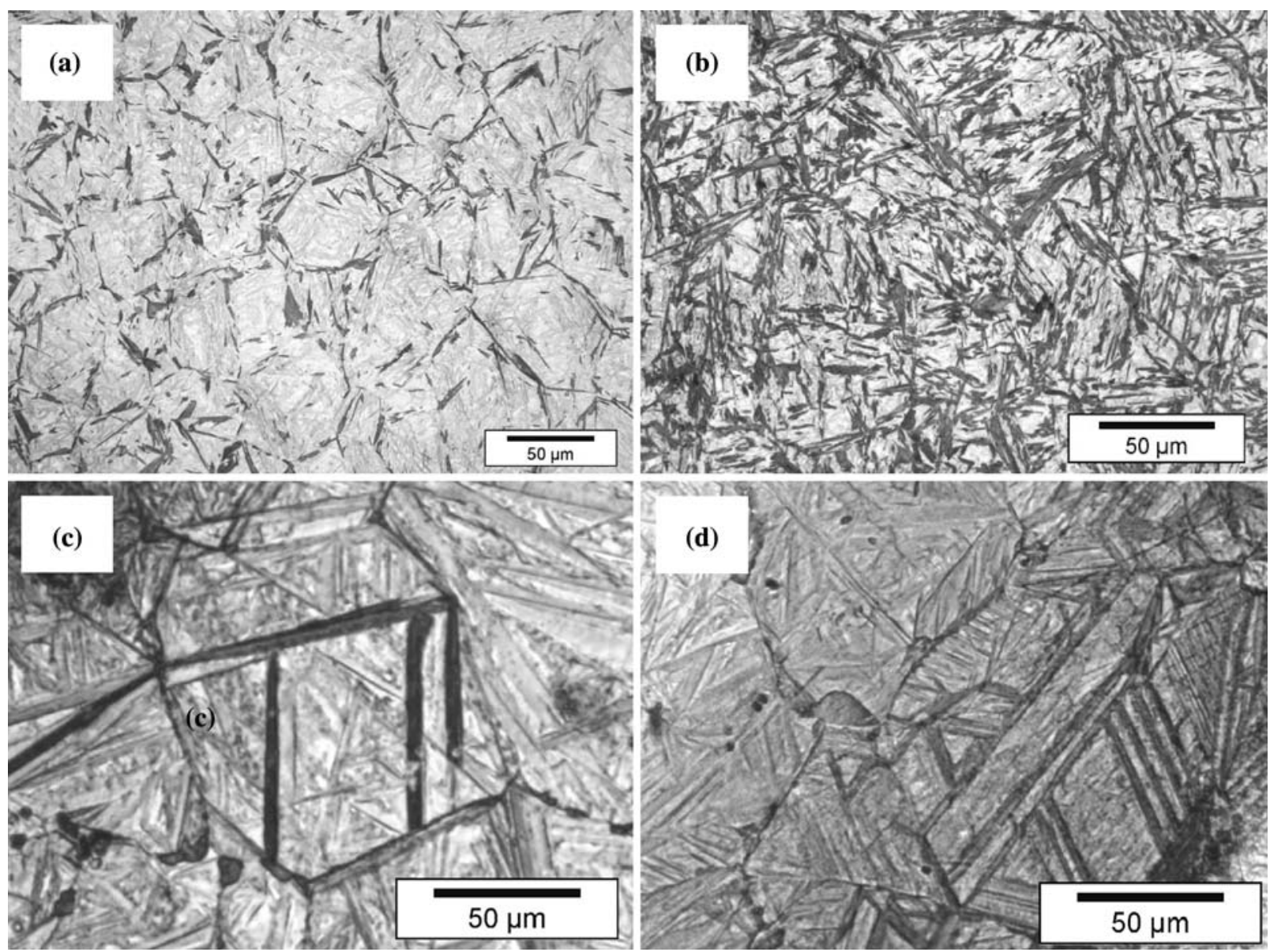

Fig. 10-(a) Microstructure after austenitizing at $T_{\text {aus }}=1050{ }^{\circ} \mathrm{C}$, quenching to $T_{1}=210{ }^{\circ} \mathrm{C}$, tempering at $T_{2}=300{ }^{\circ} \mathrm{C}$, and cooling to room temperature. (b) Microstructure after austenitizing at $T_{\text {aus }}=1050{ }^{\circ} \mathrm{C}$, quenching to $T_{1}=175{ }^{\circ} \mathrm{C}$, tempering at $T_{2}=300{ }^{\circ} \mathrm{C}$, and cooling to room temperature. $(c)$ and $(d)$ Microstructure at a polished surface after austenitizing at $T_{\text {aus }}=1050{ }^{\circ} \mathrm{C}$, during which the austenite grain boundaries are revealed by thermal etching, and quenching to $T_{1}=245^{\circ} \mathrm{C}$, tempering at $T_{2}=300{ }^{\circ} \mathrm{C}$, and cooling to room temperature.

subsequently cooled to room temperature. It can be calculated that a difference in the volume fraction austenite of more than 3 vol pct results in a significant difference in the thermal contraction, but this is clearly not observed in Figure 9.

\section{Microstructural Analysis of the Evolution of Martensite Formation}

To obtain a better understanding of the evolution of martensite in an austenitic matrix, the metallographic technique for measuring martensite first described by Greninger and Troiano ${ }^{[]}$was applied to various samples of $\mathrm{Fe}-0.80 \mathrm{C}$. In this way, we can investigate where the martensite plates or laths are formed at the early stage of transformation and how the transformation evolves subsequently with decreasing temperature. The principles involved in this technique and the associated heat treatment have been described in detail by Grange and Stewart. ${ }^{[2]}$ They studied an eutectoid carbon steel and determined the kinetics of martensite formation by metallographic examination of samples that were first quenched to a certain temperature $T_{1}$ below $M_{s}$, and subsequently, the initially formed martensite was briefly tempered at a temperature $T_{2}$ above $M_{s} \cdot{ }^{[2]}$ After the tempering step, the samples were quenched to room temperature and etched with picral to distinguish the initial martensite, which is tempered, and thus dark etching, from the martensite formed during the final quench, which appears light gray. In the present study, a number of samples were heat treated according to the preceding procedure in order to identify the initially formed martensite in the final microstructure.

The microstructures of a sample $\mathrm{Fe}-0.80 \mathrm{C}$ with $T_{\text {aus }}=1050{ }^{\circ} \mathrm{C}$, quenched to $T_{1}=210{ }^{\circ} \mathrm{C}$ and tempered at $T_{2}=300{ }^{\circ} \mathrm{C}$, are shown in Figure 10(a). The dark-etched phase is the initially formed martensite. Figure 10(b) shows the microstructure at a later stage of transformation $\left(T_{1}=175{ }^{\circ} \mathrm{C}\right)$, which indicates that the (40 to $50 \mathrm{pct}$ ) martensite formed is rather homogeneously distributed in the matrix. It is interesting to note that Grange and Stewart made very similar observations and that they suggested that the prior austenite grain boundaries are the most preferred regions for nucleation of martensite. Indeed, the dark-etching initially formed martensite in Figure 10(a) seems to outline the prior austenite grain structure at some regions, but the apparent grain size corresponding to the dark-etching 
structure is rather small compared to the austenite grain size of approximately $130 \mu \mathrm{m}$. Therefore, additional experiments were conducted with the objective to reveal both the prior austenite grain structure and the firstformed martensite. Samples Fe-0.80C were polished prior to the Greninger-Troiano heat treatment. The microstructures observed at the polished surface after the heat treatment and picral etching are shown in Figures 10(c) and (d). It is seen that the first-formed martensite plates do not have a preference to form along the austenite grain boundary, but across austenite grains. Probably, the initially formed plates nucleate at a grain boundary and their growth is stopped at another grain boundary. It is noted that a free surface may alter the transformation behavior to some extent, because a free surface reduces the volumetric constraint around martensite plates. It is difficult to quantify this effect, but it may explain the markedly different martensite morphology seen in Figure 10(c) compared to Figure 10(a).

In relation to the preceding observations, it is noted that the hypothesis that the austenite grain boundaries are the preferred regions for nucleation of martensite cannot fully explain why $M_{S}$ of a large-grained structure is higher ${ }^{[8,10,11]}$ and why the overall kinetics are virtually independent of the prior austenite grain size. ${ }^{[7]}$ On the contrary, one would expect that the overall kinetics would increase for a fine-grained structure if the grain boundaries are the preferred nucleation sites and nucleation is rate determining. However, this is not the case, and therefore, the $\gamma$ grain boundaries cannot be envisaged to play a very important role at each stage of transformation. This is consistent with the work of Kajiwara, who also concluded that the nucleation of martensite is not simply related to grain boundaries, but that the plastic accommodation of the shape strain in austenite is the most important step in the event of martensite formation. ${ }^{[8]}$

\section{DISCUSSION}

\section{A. Mechanical Stabilization of Austenite Due to a Displacive Transformation}

Comparison of the evolution of martensite formation in samples Fe-0.80C with a bainitic/austenitic microstructure (Figure 6) with the transformation characteristics in $\mathrm{Fe}-0.46 \mathrm{C}$ and $\mathrm{Fe} 0.66 \mathrm{C}$ with a ferritic/austenitic microstructure (Figures 3 and 4) indicates that the stabilization of the austenite during a partial bainitic transformation is of a different nature than the chemical stabilization of austenite during intercritical annealing. This difference in stabilization mechanism is also directly apparent from Figure 5, and based on these observations and considerations, it is argued that the linear decrease of $T_{\mathrm{KM}}$ with increasing fraction of bainite shown in Figure 8 ( $x_{\mathrm{C}}^{\gamma}$ constant) is best explained by mechanical stabilization of the austenite. ${ }^{[22,23]}$ The displacive growth of bainite is accompanied with a shape change of the grains, which leads to a plastic deformation of the surrounding austenite. The increased strength of the austenite means that a higher driving force is needed to initiate the transformation to martensite, and therefore the start temperature $T_{\mathrm{KM}}$ for the remaining austenite is decreased. It is also seen in Figure 8 that the stabilization effect becomes stronger at lower bainite formation temperatures. Probably, recovery of the plastically deformed austenite occurs concurrently with the transformation to bainite. The recovery is assumed to be more pronounced at high temperature, and therefore, the stabilization effect becomes less for higher $T_{\mathrm{b}}$.

Based on the stabilizing effect of bainite, it seems plausible to assume that also the martensite strengthens the surrounding austenite during its formation, and that this mechanical stabilization impedes the plastic accommodation of the subsequent transformation. When a martensite lath or plate is formed, dislocations are generated in the surrounding austenite by plastic deformation due to the volumetric and shear strains. On the one hand, the dislocations produced in the austenite during transformation can assist the subsequent nucleation of martensite, ${ }^{[2]}$ which is known as autocatalytic nucleation. ${ }^{[21]}$ However, the dislocations induced in the austenite due to prior transformation can also retard the subsequent transformation to martensite, which is known as mechanical stabilization. ${ }^{[22,23,25]}$ The dislocation debris interferes with the movement of the glissile interface that constitutes the growth. When the strain buildup in the remaining austenite accompanying the transformation exceeds a critical value, the further transformation at a certain temperature below $M_{\mathrm{s}}$ is suppressed. ${ }^{[26]}$ In this sense, mechanical stabilization can play an essential role in the athermal character of the martensitic transformation in carbon steels.

\section{B. Rationalization of the Athermal Transformation Kinetics}

Consider that a decrease in temperature $d T$ below $M_{S}$ results in the formation of a new number of plates or laths per unit volume of austenite, $d N$, with an average volume $V_{m}$. The shape deformation accompanying the formation of this volume of martensite increases the strength of the remaining austenite and stops the transformation. The driving force at $M_{s}$ is approximately $1700 \mathrm{~J} / \mathrm{mol}$, of which about $600 \mathrm{~J} / \mathrm{mol}^{[27,28]}$ is considered to be stored in the surrounding austenite as strain energy $E_{S}$. Since the resistance of the remaining austenite against plastic deformation has increased due to the formation of $d N$ plates, an increase in driving force is required for the transformation to recommence. It seems plausible to assume that the strain energy accompanying the subsequent transformation is larger, and that the increase in the required strain energy $d E_{S}$ is proportional to the volume of martensite due to the temperature decrease $d T$ and can be written as

$$
d E_{S}=\chi V_{m} d N
$$

with $\chi$ a proportionality constant. The change in volume fraction of martensite is given by ${ }^{[6]}$

$$
d f=(1-f) V_{m} d N
$$

where $(1-f)$ is the volume fraction of austenite available for further transformation. The transformation 
progresses with decreasing temperature when $d E_{S}$ is balanced by the increase of the chemical driving force of the remaining austenite $d(\Delta G)$ :

$$
d E_{S}=d(\Delta G)
$$

By combining Eqs. [6] through Eq. [8], it follows that

$$
d f=(1-f) \frac{1}{\chi} \frac{d(\Delta G)}{d T} d T
$$

Solving this differential equation and integrating from $T_{\mathrm{KM}}(f=0)$ to $T$ leads to Eq. [1], the KM equation, with

$$
\alpha_{m}=\frac{1}{\chi} \frac{d(\Delta G)}{d T}
$$

Calculations with MT-DATA for Fe-0.80C yield a fairly constant value for $d(\Delta G) / d T=6.9 \mathrm{~J} / \mathrm{mol} \mathrm{K}$, and analysis of the experimental kinetics of $\mathrm{Fe}-0.80 \mathrm{C}$ resulted in $\alpha_{m}=0.0131 \mathrm{~K}^{-1}$. Using these values, it follows according to Eq. [10] that the proportionality constant $\chi=523 \mathrm{~J} / \mathrm{mol}$, which seems to be a reasonable value in view of the reported values of the stored strain energy. ${ }^{[27,28]}$ The values of $\chi$ for $\mathrm{Fe}-0.46 \mathrm{C}$ and $\mathrm{Fe}-0.66 \mathrm{C}$ are listed in Table IV and are of the same magnitude.

It is seen that $\chi$ increases with increasing carbon content, which is probably related to the result reported by Chatterjee and Bhadeshia that the critical value of the plastic strain becomes smaller as the carbon content of the austenite increases. ${ }^{[27]}$ The underlying reason for the fact that the rate parameter $\alpha_{m}$ becomes smaller with increasing carbon content (Eq. [2] $)^{[14]}$ is possibly related to a combination of both a relatively strong solid solution strengthening effect of carbon, which plays an important role in the resistance to the interface motion, ${ }^{[27,29]}$ and increased dislocation strengthening for higher carbon steels.

In the athermal martensite model proposed previously, it is assumed that the local austenite strength determines the transformation temperature of a certain region. The transformation of such a region to martensite leads to an increase in the strength of the surrounding austenite, and therefore, each austenite region has a specific decomposition temperature. Thus, in the present model, the nucleation at certain defects is not considered to be the rate-controlling step in the transformation, but the resistance of the austenitic parent phase to the growth of the nuclei. This explanation for the athermal nature of the martensitic transformation is consistent with the "growth-resistance of

Table IV. The Rate Parameter $\alpha_{m}$ and the Proportionality Constant $\chi$

\begin{tabular}{lccc}
\hline Alloy & $\alpha_{m}\left(\mathrm{~K}^{-1}\right)$ & $d(\Delta G) / d T(\mathrm{~J} / \mathrm{mol} \mathrm{K})$ & $\chi(\mathrm{J} / \mathrm{mol})$ \\
\hline Fe-0.46C & 0.0168 & 7.0 & 417 \\
Fe-0.66C & 0.0146 & 7.2 & 493 \\
Fe-0.80C & 0.0132 & 6.9 & 523 \\
\hline
\end{tabular}

austenite" hypothesis proposed by Edmondson and Ko. ${ }^{[3]}$ By means of metallographic examination, they demonstrated that the formation of martensite is accompanied by a reasonable amount of plastic deformation, and that the deformation has an effect on the subsequent transformation.

Based on the micrographs seen in Figure 10 and consideration of the local strength of the austenite that determines the resistance against plastic deformation and thus the strain energy involved in the formation of martensite plates or laths, it is postulated that the initial formation of martensite occurs preferably in the grain interior, which is assumed relatively soft compared to the grain boundary regions. ${ }^{[11]}$ The first-formed martensite plates effectively divide the prior austenite grain and strengthen the surrounding austenite, and the subsequent formation of martensite plates in the same grain require a larger driving force. This hypothesis is in accordance with the analysis by Kajiwara of the austenite yield stress and the driving force at $M_{S}$ for $\mathrm{Fe}-\mathrm{Ni}$ alloys. ${ }^{[8]}$ Kajiwara argued that the energy expended in deforming the austenite in order to accommodate the shear strain, $W$, is proportional to the yield stress, and he demonstrated that the increase in the required driving force for fine-grained specimens corresponds to an increase in $W$ due to the increase in yield stress with grain refinement. This relationship proposed by Kajiwara is in general agreement with the starting assumptions of the KM relation in the present study, since it seems plausible to assume that the yield stress of the remaining austenite increases also due to the deformation induced by the displacive transformation itself.

\section{CONCLUSIONS}

The progress of martensite formation in partially and fully austenitic plain carbon steels has been determined using dilatometry. The characteristics of martensite formation in partially austenitic steels after intercritical annealing can be quantitatively explained by carbon enrichment of the remaining (intercritical) austenite. In contrast, this chemical stabilization mechanism of austenite cannot explain the transformation characteristics of the remaining austenite after a partial transformation to bainite in lean-Si steels. It is therefore concluded that the stabilization of austenite due to a partial transformation to bainite is of a mechanical nature: the austenite is strengthened due to the shape change accompanying the transformation. Finally, it is postulated that the typical progress of the transformation to martensite with decreasing temperature, which can be described by a natural decay function, the $\mathrm{KM}$ equation, is a consequence of the increase in strength of the remaining austenite as the transformation progresses. Thus, in the present model of the martensitic transformation, the plastic accommodation in the austenite of the deformation strain is considered to be the critical step in the formation of athermal martensite. 


\section{OPEN ACCESS}

This article is distributed under the terms of the Creative Commons Attribution Noncommercial License which permits any noncommercial use, distribution, and reproduction in any medium, provided the original author(s) and source are credited.

\section{REFERENCES}

1. A.B. Greninger and A.R. Troiano: Trans. ASM, 1940, vol. 28, pp. $537-74$.

2. R.A. Grange and H.M. Stewart: Trans. AIME, 1946, vol. 167, pp. 467-90.

3. B. Edmondson and T. Ko: Acta Metall., 1954, vol. 2, pp. 235-41.

4. L. Kaufman and M. Cohen: Prog. Met. Phys., 1958, vol. 7, pp. $165-246$.

5. D.P. Koistinen and R.E. Marburger: Acta Metall., 1959, vol. 7, pp. $59-60$.

6. C.L. Magee: Phase Transformations, ASM, Metals Park, OH, 1970, pp. 115-55.

7. A.S. Sastri and D.R.F. West: J. Iron Steel Inst., 1965, vol. 203, pp. 138-49.

8. S. Kajiwara: Metall. Trans. A, 1986, vol. 17A, pp. 1693-702.

9. E.M. Breinan and G.S. Ansell: Metall. Trans., 1970, vol. 1, pp. $1513-23$.

10. T.J. Nichol, G. Judd, and G.S. Ansell: Metall. Trans. A, 1977, vol. 8A, pp. 1877-83.

11. P.J. Brofman and G.S. Ansell: Metall. Trans. A, 1983, vol. 14A, pp. 1929-31.
12. T.A. Kop, J. Sietsma, and S. Van der Zwaag: J. Mater. Sci., 2001, vol. 36, pp. 519-26.

13. S.M.C. Van Bohemen, M.J. Santofimia, and J. Sietsma: Scripta Mater., 2008, vol. 58, pp. 488-91.

14. S.M.C. Van Bohemen and J. Sietsma: Mater. Sci. Technol., in press, DOI 10.1179/174328408X365838.

15. E. Gillam and D.G. Cole: Phil. Mag., 1953, vol. 44, pp. 999-1009.

16. R. Pradhan and G.S. Ansell: Metall. Trans. A, 1978, vol. 9A, pp. 793-801.

17. K.W. Andrews: J. Iron Steel Inst., 1965, vol. 203, pp. 721-29.

18. P. Payson and C.H. Savage: Trans. ASM, 1944, vol. 33, pp. 26175.

19. A.E. Nehrenberg: Trans. AIME, 1946, vol. 167, pp. 494-98.

20. P.J. Jacques, E. Girault, P. Harlet, and F. Delannay: ISIJ Int., 2001, vol. 41, pp. 1061-70.

21. H.K.D.H. Bhadeshia: Bainite in Steels, The Institute of Materials, London, 2001

22. E.S. Machlin and M. Cohen: Trans. AIME, 1951, vol. 191, pp. $267-74$.

23. J.R. Strife, M.J. Carr, and G.S. Ansell: Metall. Trans. A, 1977, vol. 8A, pp. 1471-83.

24. G.B. Olson and M. Cohen: Metall. Trans. A, 1975, vol. 6A, pp. 791-95.

25. H.K.D.H. Bhadeshia: Mater. Sci. Eng. A, 1999, vol. 275, pp. 5866.

26. S. Chatterjee, H.S. Wang, J.R. Yang, and H. Bhadeshia: Mater. Sci. Technol., 2006, vol. 22, pp. 641-44.

27. S. Chatterjee and H.K.D.H. Bhadeshia: Mater. Sci. Technol., 2007, vol. 23, pp. 1101-04.

28. J.W. Christian: in ICOMAT'79, G.B. Olson and M. Cohen, eds., MIT, Boston, MA, 1979, pp. 145-54.

29. K.J. Irvine, T. Gladman, and F.B. Pickering: J. Iron Steel Inst., 1969, vol. 207, pp. 1017-28. 